\title{
PENINGKATAN EFISIENSI PRODUKSI JENANG DAN KUE KACANG DI KOPERASI WANITA "MITRA WANITA" DI KECAMATAN KANIGORO, KABUPATEN BLITAR
}

Increasing Eficiency of Jenang and Peanut Cookies Production at Koperasi Wanita "Mitra Wanita", District Kanigoro, Blitar Regency)

\section{Novita Wijayanti dan Rosalina Ariesta Laeliocattleya}

PS Ilmu dan Teknologi Pangan, Jurusan Teknologi Hasil Pertanian

Fakultas Teknologi Pertanian, Universitas Brawijaya, Jl. Veteran, Malang

*Email korespondensi penulis: n_wijayanti@ub.ac.id; wijayantinovita@gmail.com

\begin{abstract}
Koperasi Wanita "Mitra Wanita" in Tlogo Village, Kanigoro District, Blitar Regency is a group of women who have a food processed businesses. They used manually equipment that less efficient in the process of its products. The condition causes the production capacity was still limited. The activities of "IbM Koperasi Wanita Mitra Wanita" program aimed to help UKM in improving production efficiency through technology transfer of production equipment. So, the various problems of UKM in Koperasi Wanita "Mitra Wanita" were getting solutions. The technology transfer was implemented in this program, for example: jenang stirrer machine and coconut shredding machine for jenang ketan producer, also mixer and oven for peanut cookies producer. The program was implemented by training, mentoring and testing equipments to ensure the efficiency of technology transfer and also mentoring implementation of Good Manufacturing Practice (GMP). The result of technology transfer showed an increasing of the production efficiency. The use of shorter time can obtain results with greater capacity and better quality.
\end{abstract}

Keywords: efficiency of production, jenang ketan, peanut cookies

\begin{abstract}
ABSTRAK
Koperasi Wanita "Mitra Wanita" di Desa Tlogo, Kecamatan Kanigoro, Kabupaten Blitar merupakan sekumpulan wanita yang memiliki usaha olahan pangan. UKM tersebut masih menggunakan peralatan manual sehingga kurang efisien dalam proses produksinya. Kondisi tersebut menyebabkan kapasitas produksi masih terbatas. Kegiatan IbM Kelompok Usaha Bersama Mitra Wanita ini bertujuan untuk membantu UKM dalam meningkatkan efisiensi produksi melalui alih teknologi peralatan produksi sehingga berbagai permasalahan yang dihadapi UKM dalam Koperasi Wanita "Mitra Wanita" ini memperoleh solusi. Alih teknologi yang dilaksanakan dalam program ini adalah alat pengaduk jenang dan mesin pemarut kelapa untuk produsen jenang ketan, serta mixer dan oven untuk produsen kue kacang. Program ini dilaksanakan dengan pelatihan, pendampingan dan uji coba alat untuk memastikan efisiensi alih teknologi serta pendampingan penerapan Cara Pengolahan Pangan yang Baik (CPPB). Hasil alih teknologi menunjukkan adanya peningkatan efisiensi produksi. Penggunaan waktu yang lebih singkat dapat memperoleh hasil dengan kapasitas yang lebih besar dan kualitas yang lebih baik.
\end{abstract}

Kata kunci: efisiensi produksi, jenang ketan, kue kacang 


\section{PENDAHULUAN}

Desa Tlogo merupakan salah satu desa di Kecamatan Kanigoro yang merupakan desa agraris. Pengembangan Kecamatan Kanigoro sebagai ibukota Kabupaten Blitar yang merupakan salah satu dari kota agropolitan di Jawa Timur telah berimbas pada pemberdayaan desa tersebut sebagai desa yang bergerak dalam bidang agribisnis. Merespon hal tersebut, para wanita aktif di desa tersebut mendirikan Koperasi Wanita (Kopwan) "Mitra Wanita" pada Oktober 2009.

Saat ini koperasi wanita tersebut mempunyai anggota 73 orang dan bergerak di bidang simpan pinjam dan usaha olahan pangan di Desa Tlogo, Kecamatan Kanigoro, Kabupaten Blitar. Beberapa industri UKM yang tergabung dalam kopwan "Mitra Wanita" seperti produksi kue kembang goyang (matari), opak gambir, kue kering kacang, jenang ketan, dan kue basah. Usaha olahan pangan yang menonjol dari kopwan tersebut adalah jenang ketan khas Blitar dan kue kacang. Kedua produk tersebut dipasarkan dengan merek "Rasa" oleh kopwan "Mitra Wanita".

Jenang ketan merupakan suatu olahan pangan yang dibuat dari campuran tepung beras ketan, gula kelapa, santan kelapa, yang didihkan hingga menjadi kental dan berminyak tidak lengket, dan apabila dingin pasta akan menjadi padat, kenyal dan dapat diiris. Jenis dodol sangat beragam tergantung keragaman campuran tambahan dan juga cara pembuatannya (Haryadi, 2006).

Jenang ketan diproduksi oleh Ibu Tumiyah. $\mathrm{Bu}$ Tumiyah adalah ketua koperasi wanita "Mitra Wanita". Setiap hari bu Tumiyah memproduksi $10 \mathrm{~kg}$ jenang ketan. Namun ketika mendekati hari raya atau mendapat pesanan hajatan bisa memproduksi hingga $20 \mathrm{~kg}$ per hari. Jenang ketan merek "Rasa" dan PIRT No. 2063505020801-20 dikemas dalam kemasan unik menggunakan kemasan anyaman bambu dengan berat bersih $1,2 \mathrm{~kg}$ dan dijual dengan harga Rp. 35.000. Produk tersebut dapat dilihat pada Gambar 1 .

$\mathrm{Bu}$ Tumiyah mengolah jenang dengan bahan baku $10 \mathrm{~kg}$ (5 kg tepung ketan dan 5 $\mathrm{kg}$ gula merah). Tepung ketan merupakan bahan baku utama jenang. Bahan baku lain adalah gula merah yang diiris halus dan dibuat larutan kental (Bahasa Jawa: juruh). Kelapa juga merupakan bahan baku yang diparut kemudian dibuat santan. Selanjutnya santan dibuat minyak kelapa dengan cara dipanaskan dalam waktu lama sampai minyak terpisah dari air.

Pada saat pemanasan dengan keberadaan cukup banyak air, pati yang terkandung dalam tepung menyerap air dan membentuk pasta yang kental, dan pada saat dingin pati membentuk massa yang kenyal, lenting dan liat. Penggunaan beras ketan $20 \%$ dapat menghasilkan mutu jenang yang baik karena pada saat pemasakan menghasilkan pasta yang kental, kenyal, dan khalis (Haryadi, 2006).

Ciri khas jenang ketan produksi Ibu Tumiyah adalah penambahan tape yang terbuat dari nasi. Tape nasi ini dibuat sendiri dengan cara meambahkan ragi tape pada nasi kemudian difermentasi selama 2-3 hari. Tape nasi ini selain memberikan rasa khas yaitu agak sedikit asam, juga membantu mengawetkan produk. Proses fermentasi seringkali menghasikan produk metabolit sekunder yang berfungsi menghambat pertumbuhan mikroba (Fardiaz, 1992).

Jenang ketan produksi $\mathrm{Bu}$ Tumiyah dapat bertahan tanpa pengawet selama 1 bulan. Jika tidak menggunakan tape nasi, maka daya tahan produk hanya 2 minggu. Produk jenang ketan merk "Rasa" selain dijual di outlet koperasi wanita "Mitra Wanita", juga dipasarkan ke grosir dalam bentuk sistem jual putus atau konsinyasi.

Kue kacang diproduksi oleh Ibu Siti Nafiroh dengan merk "Rasa". Setiap hari bu Nafiroh memproduksi $10 \mathrm{~kg}$ kue kacang. Kue kacang dikemas dalam toples berukuran 4 ons dengan harga jual Rp. 22.000, toples ukuran 200 gram dijual dengan harga Rp. 14.000, atau dijual tanpa kemasan per kg Rp. 45.000. Semua produk tersebut 
dipasarkan melalui kopwan "Mitra Wanita". Keuntungan bagi kedua mitra adalah 20$30 \%$ dari harga jual.

Kue kacang termasuk makanan ringan berbentuk cookies. Cookies adalah kue yang diproduksi dengan cara mencampur adonan dan keudian dipanggang. Cookies terbuat dari tepung atau pati, ada yang difermentasi atau tidak, serta mengandung makanan bergizi lainnya. Tepung dapat berasal dari buah, daun, sereal, umbi, dan komoditas hortikultura lainnya. Istilah "cookies" umumnya diikuti oleh zat yang mencirikannya seperti kacang-kacangan, madu, wortel, coklat dll. Bahan lainnya juga bisa digunakan untuk meningkatkan kemampuan fisik, nutrisi, sensoris, atau sifat teknologi seperti enzim, pewarna, vitamin, mineral, serat dan perasa (Moreto, 1999).

Pengolahan kue kacang dimulai dari penepungan kacang tanah yang sudah disangrai dengan menggunakan blender kecil. Selanjutnya gula dan margarin dikocok dan dimasukkan telur. Terigu dimasukkan sedikit demi sedikit sambil diuleni. Adonan yang sudah terbentuk kemudian dicetak, diolesi telur, dan ditaburi wijen. Adonan yang sudah dicetak kemudian dipanggang dalam oven skala rumah tangga. Setelah matang dan didinginkan, kue kacang dikemas dalam toples kecil dan besar atau dijual per kg. Ibu Siti Nafiroh memasarkan kue kacang di outlet koperasi wanita dengan sistem konsinyasi. Seringkali juga mitra mendapat pesanan untuk hajatan.

Secara umum kedua UKM tersebut menjalankan usahanya secara manual dan tradisional, padahal mereka memiliki daya terima pasar yang cukup baik. Terlebih lagi jika mendapatkan pesanan yang cukup banyak seperti saat hari raya atau hajatan, maka mereka menghadapi masalah kapasitas produksi yang masih rendah karena proses produksi yang manual dan berjalan lambat. Selain permasalahan tersebut, UKM juga membutuhkan bimbingan dan pendampingan dalam menerapkan CPPB (Caracara Pengolahan Pangan yang Baik). Hal ini dilakukan agar UKM dapat menjamin kesehatan dan keamanan pangan.

Penerapan alih teknologi sesuai dengan permasalahan mitra diharapkan mampu menjadi solusi terutama dalam peningkatan efisiensi dan kapasitas produksi.

Tujuan yang ingin dicapai dalam kegiatan ini adalah meningkatkan kapasitas dan efisiensi produksi serta memperbaiki kualitas produk dan pengemasan bagi anggota Koperasi Wanita "Mitra Wanita" di Desa Tlogo, Kecamatan kanigoro dan Kabupaten Blitar. Kelak diharapkan dapat meningkatkan daya saing Mitra di pasaran serta mendukung Program Pemerintah Kabupaten Blitar untuk pemberdayaan masyarakat kecil serta meningkatkan pendapatan daerah.

\section{METODE PELAKSANAAN}

Tahapan kegiatan yang dilakukan pada IbM Koperasi Wanita "Mitra Wanita" ini meliputi:

1. Melakukan identifikasi mengenai segala permasalahan yang dihadapi oleh Mitra UKM yang tergabung dalam Koperasi Wanita "Mitra Wanita"

2. Melakukan diskusi dengan Mitra untuk pelaksanaan kegiatan meliputi bantuan alih teknologi, pendampingan serta pembinaan tentang teknologi pengolahan pangan yang memenuhi standard industri yang kompetitif.

3. Pengadaan fasilitas mesin dan peralatan untuk mendukung peningkatan efisiensi produksi di Koperasi Wanita "Mitra Wanita".

4. Kegiatan bimbingan teknis, pelatihan dan pendampingan mengenai pemakaian dan perawatan mesin dan peralatan

5. Pendampingan dalam penerapan $\mathrm{CPPB}$ dalam proses pengolahan produk pangan oleh kedua mitra. Pembinaan sikap pencegahan terhadap kesalahan yang berakibat kontaminasi makanan dengan tindakan tepat dan didukung dengan penggunaan fasilitas yang bersih

6. Perbaikan dalam bentuk kemasan agar lebih menarik, lebih mudah dalam 
mengkonsumsi, lebih tahan lama dan lebih memperhatikan keseragaman mutu kemasan.

\section{HASIL DAN PEMBAHASAN}

Khalayak sasaran strategis yang dilibatkan dalam pelaksanaan kegiatan pengabdian kepada masyarakat ini adalah Koperasi Wanita "Mitra Wanita" di Desa Tlogo, Kecamatan Kanigoro, Kabupaten Blitar yang mengolah produk pangan, meliputi: jenang ketan dan kue kacang yang disajikan dalam Gambar 1.

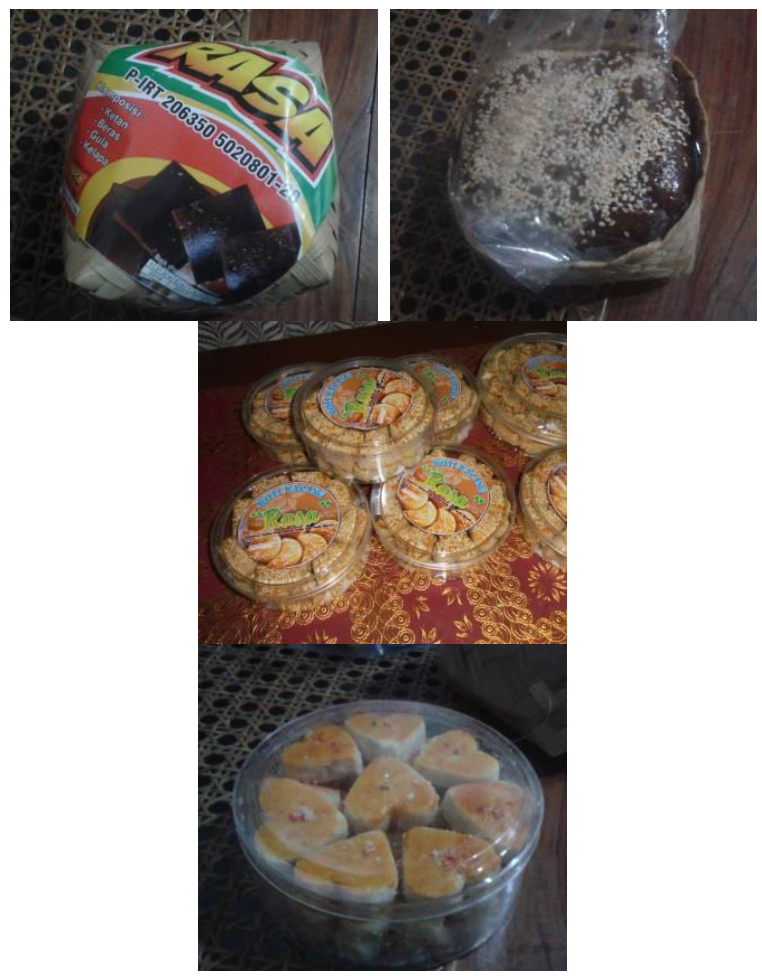

Gambar 1. Jenang Ketan dan Kue Kacang Merk "Rasa"

Program IbM ini ditujukan untuk menyelesaikan permasalahan yang dihadapi oleh Koperasi Wanita "Mitra Wanita" berdasar pada masing-masing permasalahan yang dihadapi mitra yaitu meliputi:

\section{Peningkatan Efisiensi Produksi Jenang Ketan}

Mekanisasi produksi jenang ketan diperlukan untuk meningkatkan efisiensi proses sehingga berdampak pada peningkatan kapasitas produksi mitra.
Peningkatan kapasitas produksi dilakukan dengan alih teknologi alat pengaduk jenang.

Selama ini, proses pembuatan jenang diaduk secara manual dengan menggunakan tenaga manusia. Pemasakan manual dengan menggunakan tenaga manusia terkendala tenaga yang diperlukan cukup menguras energi karena selain lama mengaduk, kondisi yang panas menyebabkan pekerja yang memasak jenang cepat lelah. Frekuensi adukan yang tidak konstan menyebabkan jenang tidak segera kalis. Proses pemasakan yang lama membutuhkan waktu 4-5 jam untuk $10 \mathrm{~kg}$ jenang.

Peningkatan efisiensi dalam pemasakan jenang, melalui alih teknologi mesin pengaduk mekanis. Penggunaan alat ini mempersingkat waktu pemasakan karena jenang cepat kalis dengan adukan yang stabil dan pemanasan yang rata. Selain mengurangi tenaga kerja, alat dengan kapasitas $20 \mathrm{~kg}$ dalam sekali proses dapat meningkatkan jumlah produksi. Alat pengaduk jenang tersebut dapat dilihat pada Gambar 2.

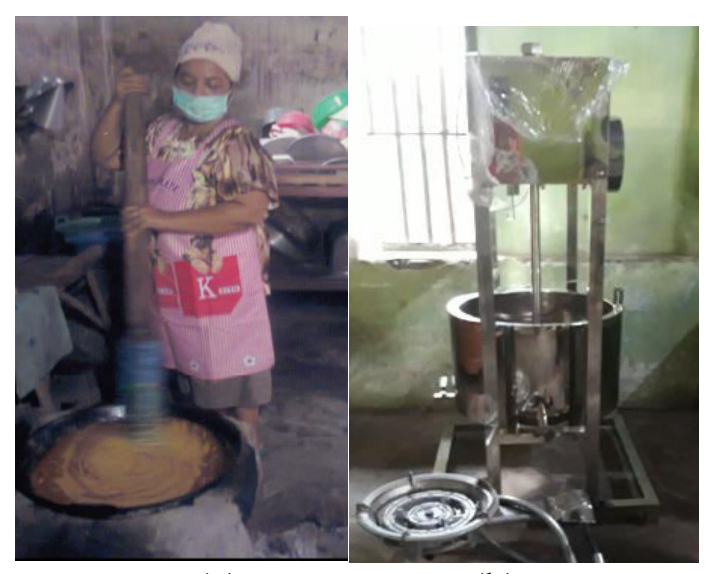

(a)

(b)

Gambar 2. Peralatan yang Digunakan dalam Pemasakan Jenang (a) alat lama, (b) alat baru

Pada proses pembuatan jenang ketan diperlukan minyak kelapa. Selama ini Mitra 1 membuat santan dengan cara memarut kelapa secara manual sehingga membutuhkan waktu yang lama. Namun jika memperoleh pesanan yang banyak maka kelapa diparutkan di pasar yang terletak cukup jauh dari rumahnya. Oleh karena itu 
peralatan lain yang dibutuhkan oleh produsen jenang ketan adalah mesin pemarut kelapa (Gambar 3). Dengan menggunakan mesin ini dapat menghasilkan kelapa parut dalam jumlah banyak dengan waktu singkat. Kira-kira satu butir kelapa dapat diparut selama 1-2 menit

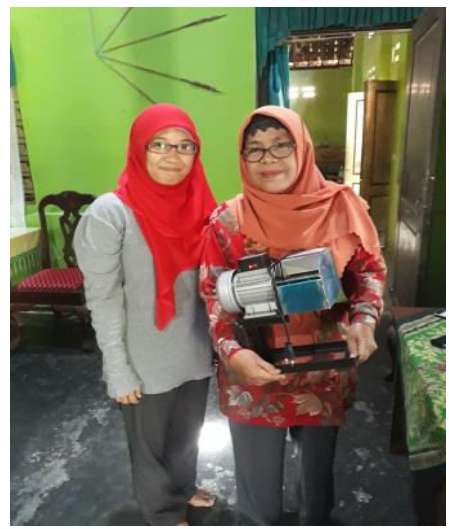

Gambar 3. Mesin Pemarut Kelapa

\section{Peningkatan Efisiensi Produksi Kue Kacang}

Peningkatan efisiensi produksi kue kacang dilakukan dengan menyediakan oven dengan kapasitas yang lebih besar. Selama ini Mitra menggunakan oven rumah tangga dengan kapasitas kecil. Untuk adonan kue kacang yang menggunakan terigu $5 \mathrm{~kg}$ membutuhkan waktu selama 6-7 jam proses pemasakan. Biasanya jika mitra mendapatkan banyak pesanan selalu meminjam dari tetangga agar proses pemasakan kue kacang dapat lebih cepat. Kapasitas oven baru sekitar dua kali lipat oven tradisional yang dimiliki Mitra (Gambar 4).

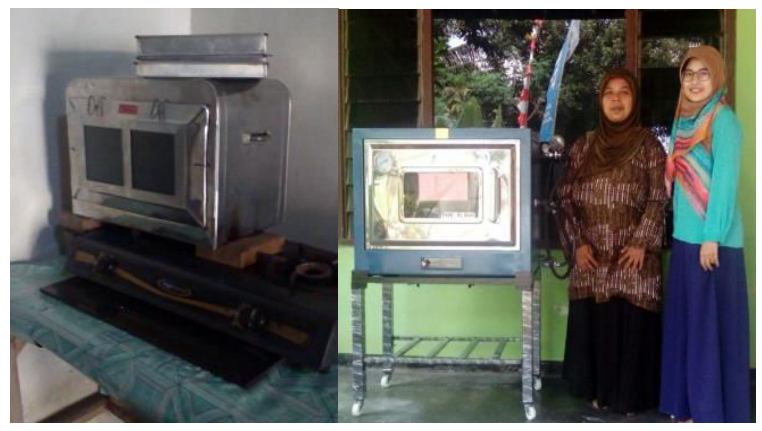

(a)

(b)

Gambar 4. (a) Oven Rumah Tangga, (b) Oven Kapasitas Besar
Penggunaan oven dengan kapasitas besar ini dapat meningkatkan kapasitas produksi kue kacang. Selain itu juga lebih menghemat bahan bakar karena sekali melakukan pemanggangan dapat dapat dilakukan dalam jumlah yang lebih banyak.

Selain oven, Mitra juga membutuhkan mixer untuk mengefisienkan pencampuran adonan kue kacang. Selama ini, Mitra melakukan proses pencampuran adonan dengan menggunakan tangan. Sebenarnya bisa menggunakan mixer rumah tangga, namun karena jenis adonannya berat maka mesin mixer dapat cepat panas dan hal ini akan merusak mesin.

Pada IbM ini dilakukan pengadaan mixer yang dapat mengaduk adonan yang berat seperti roti yang dapat dilihat pada Gambar 5. Pengadaan mixer berkapasitas 4,3 liter ini membantu Mitra terutama pada saat jumlah produksi cukup besar sehingga waktu pencampuran menjadi lebih singkat.

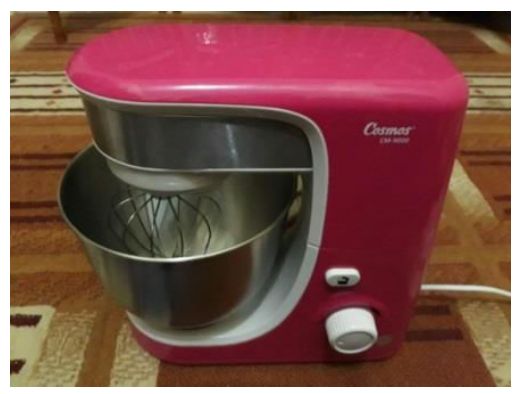

Gambar 5. Mixer

Mesin mixer pada Gambar 5 memiliki beberapa keunggulan yaitu wadah terbuat dari stainless steel sehingga lebih aman dan tahan lama, memiliki tiga kecepatan yang dapat diatur dan memiliki daya yang cukup besar untuk mencampur adonan yang berat seperti adonan roti.

\section{Pendampingan Cara Penggunaan Alat}

Tim pelaksana kegiatan harus memastikan bahwa alat yang dihibahkan dapat berfungsi dengan baik. Oleh karena itu, sebelum mesin dan peralatan digunakan oleh mitra, perlu dilakukan uji coba dan penyetelan alat. Selain itu tim pelaksana juga perlu memberikan informasi bagaimana menggunakan, merawat atau memperbaiki jika terjadi kerusakan. 


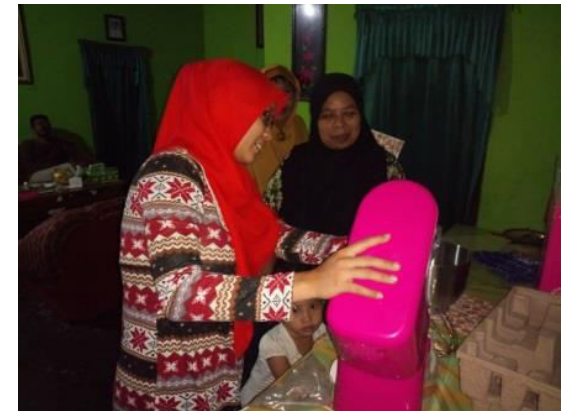

Gambar 6. Menjelaskan Cara Menggunakan dan Merawat Mixer

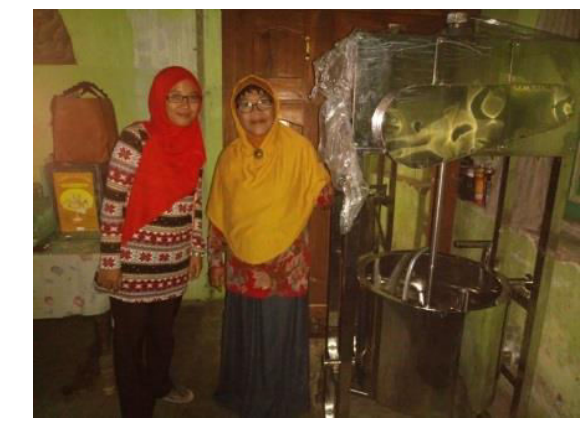

Gambar 7. Pendampingan Prosedur Penggunaan dan Perawatan Alat Pengaduk Jenang

\section{Pendampingan Penerapan Cara Pengolahan Pangan yang Baik (CPPB)}

Dari Gambar 2 dan 4 terlihat bahwa kondisi proses produksi di kedua Mitra belum higienis. Proses dengan sanitasi yang memenuhi standar belum bisa sepenuhnya diterapkan oleh Mitra. Walaupun Mitra telah berusaha memenuhi sanitasi pekerja dengan menggunakan masker, tutup kelapa, dan sarung tangan ketika mengolah makanan, tetapi sanitasi lingkungan dan peralatan belum sepenuhnya diterapkan.

Demikian pula sanitasi pekerja yang lebih lengkap perlu diaplikasikan oleh mitra. Jenang merupakan produk semi basah atau intermediate moisture food (IMF). Produk seperti ini mempunyai aktivitas air (Aw) sedang yang rentan terhadap pertumbuhan kapang (Carnovas et al., 2003).

Kondisi proses yang higienis diperlukan untuk menekan pertumbuhan kapang. Karena Mitra tidak menggunakan bahan pengawet sama sekali dalam proses produksinya. Keawetan produk diperoleh dari kadar gula yang tinggi dalam produk karena kadar gula yang tinggi mengakibatkan tekanan osmotik tinggi sehingga menghambat pertumbuhan mikroba (Srilakshmi, 2013).

Penggunaan tape nasi membantu keawetan karena tape nasi bersifat asam yang menurunkan $\mathrm{pH}$ makanan, selain kemungkinan ada produk metabolit sekunder selama fermentasi yang bersifat anti kapang. Kondisi proses yang higienis akan sangat membantu meningkatkan keawetan produk mitra.

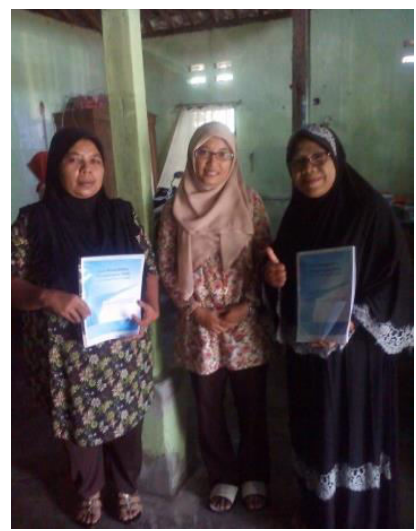

Gambar 8. Sosialisasi Cara Pengolahan Pangan yang Baik kepada Kedua Mitra

Penerapan cara pengolahan pangan yang baik (CPPB) merupakan salah satu faktor penting untuk memenuhi standar kualitas atau persyaratan keamanan pangan yang telah ditetapkan. CPPB sangat berguna bagi kelangsungan hidup industri pangan baik yang berskala kecil, sedang, maupun yang berskala besar (Wahono, 2007). Oleh karena itu dalam kegiatan ini, tim juga memberikan pengenalan dan edukasi CPPB yang selanjutnya harus diterapkan oleh Mitra.

Tindakan yang dapat dilakukan adalah memperbaiki hygiene dan sanitasi yaitu hygiene produk untuk mencegah kontaminasi, perbaikan metode penyimpanan untuk bahan baku dan produk jadi, serta melakukan pembersihan secara rutin dan benar pada mesin dan peralatan. Selanjutnya tetap diperlukan kegiatan pemantauan dalam penerapan CPPB dalam proses pengolahan produk pangan oleh mitra.

Ringkasan hasil kegiatan alih teknologi dapat dilihat pada Tabel 1. 
Tabel 1.Peningkatan Efisiensi Produksi Olahan Pangan di Kopwan "Mitra Wanita"

\begin{tabular}{|c|c|c|c|c|c|c|}
\hline \multirow{3}{*}{ Produk } & \multirow{3}{*}{ Tahapan Proses } & \multicolumn{4}{|c|}{ Jumlah dan waktu proses } & \multirow{3}{*}{$\begin{array}{c}\text { Peningkatan } \\
\text { Kapasitas }\end{array}$} \\
\hline & & \multicolumn{2}{|c|}{ Saat ini } & \multicolumn{2}{|c|}{ Setelah program } & \\
\hline & & Jumlah & Waktu & Jumlah & Waktu & \\
\hline \multirow{3}{*}{$\begin{array}{l}\text { Jenang } \\
\text { ketan }\end{array}$} & Pembuatan & 5 butir & 3 jam & 20 butir & 3 jam & 4 kali \\
\hline & kelapa & & & & & \\
\hline & Pemasakan jenang & $10 \mathrm{~kg}$ & $\begin{array}{l}4-5 \\
\text { jam }\end{array}$ & $20 \mathrm{~kg}$ & 4-5 jam & 2 kali \\
\hline \multirow{3}{*}{$\begin{array}{l}\text { Kue } \\
\text { kacang }\end{array}$} & Pengadukan adonan & $2,5 \mathrm{~kg}$ & 0,5 & $5 \mathrm{~kg}$ & 0,5 jam & 2 kali \\
\hline & & & jam & & & \\
\hline & Pemanggangan & $5 \mathrm{~kg}$ & $6 \mathrm{jam}$ & $5 \mathrm{~kg}$ & 3 jam & 2 kali \\
\hline
\end{tabular}

\section{KESIMPULAN}

Kegiatan alih teknologi yang dilakukan sangat memberikan manfaat bagi Mitra. Peningkatan efisiensi produksi pada proses pemasakan dan pemarutan kelapa pada pembuatan jenang ketan, peningkatan efisiensi pengadukan dan pemasakan pada pembuatan kue kacang memberikan manfaat positif terhadap kemampuan mitra dalam memenuhi permintaan pasar.

\section{UCAPAN TERIMA KASIH}

Ucapan terima kasih disampaikan kepada beberapa pihak, yaitu:

1. Direktorat Penelitian dan Pengabdian kepada Masyarakat, Direktorat Jenderal Pendidikan Tinggi, Kementerian Riset, Teknologi dan Pendidikan Tinggi atas pendanaan kegiatan melalui skim Iptek bagi Masyarakat (IbM) dengan Nomor penugasan: 021/SP2H/PPM/DRPM/ 2017, tanggal 3 April 2017

2. Lembaga Penelitian dan Pengabdian kepada Masyarakat Universitas Brawijaya yang telah bekerjasama dengan baik dalam pelaksanaan kegiatan IbM ini.

3. Mitra UKM yang tergabung dalam Koperasi Wanita "Mitra Wanita" yaitu Ibu Tumiyah dan Ibu Siti Nafiroh yang telah berpartisipasi aktif dalam pelaksanaan kegiatan IbM ini.

\section{DAFTAR PUSTAKA}

Carnovas G.V.B., Molina J.J.F., Alzamora S.M., Tapia M.S., Malo A.L., and Chans J.W. (2003). Handling and Preservatives of Fruits and Vegetables by Combined Methods for Rural Areas. Food and Agriculture Organization of the United Nations. Rome.

Fardiaz S. (1992). Mikrobiologi Pangan 1. PT. Gramedia Pustaka Utama. Jakarta.

Haryadi. (2006). Teknologi Pengolahan Beras. Gadjah Mada University Press. Yogyakarta. dalam Srilakshmi B. 2013. Food Science. Third Edition. New Age International Limitd Publisher. New Delhi.

Moreto, E. (1999). Processamento e Análise de biscoitos. São Paulo:Varela, p. 97.

SrilakshmiB. (2003). Food Science. Third Edition. New Age Intrnational Limitd Publisher. New Delhi.

Wahono, T. (2007). Panduan Penerapan Pedoman Cara Produksi Pangan Yang Baik Untuk Industri Rumah Tangga (CPPB-IRT). Fakultas Teknologi Pertanian. Universitas Brawijaya. Malang. 